\title{
Retrospective analysis of the spread of cat chlamydia and features of its treatment with a drug based on azithromycin
}

\author{
Alexey Strugovschikov ${ }^{1}$, Nikolay Pudovkin ${ }^{1, *}$, Petr Smutnev ${ }^{1}$, and Ivan Subbotin ${ }^{1}$ \\ ${ }^{1}$ Saratov State Agrarian University named after N. I. Vavilov, 410005, Sokolovaya Street, 335, \\ Saratov, Russia
}

\begin{abstract}
The Chlamydiales order bacteria are eukaryotic cells obligate intracellular parasites. The major purpose of the research was to study the prevalence, clinical progression and treatment of Chlamydia in cats with an azithromycin-based drug. A total of 3,388 samples for chlamydia were studied in 2019, of which 243 proved to be positive. Chlamydia was diagnosed using the polymerase chain reaction (PCR) technique. The Azithronit drug was administered $0.5 \mathrm{ml}$ per animal, 1 time per day, for 7 days. Hematological parameters were determined using the IDEXX Laser Cyte hematological analyzer, while the biochemical parameters were determined using the IDEXX Catalist analyzer (USA). In Moscow, chlamydial infection plays a significant role in the cats inflammatory eye diseases etiology. The overall infection rate of the Moscow cat population totalled $7.2 \%$. In young animals, the incidence was higher $(28.3 \%)$ than in adults $(19.5 \%)$. In terms of gender, the incidence of chlamydia in female cats $(56 \%)$ was higher than in males $(44 \%)$. The main forms of chlamydia manifestations were those of purulent and serous conjunctivitis - $69.8 \%$ and $20.5 \%$, respectively, keratitis $-8.7 \%$. The treatment with azithromycinbased drugs requires only a single daily administration for 7 days to ensure the clinical signs elimination.
\end{abstract}

\section{Introduction}

About 100 million new cases of chlamydial infection are registered annually throughout the world. The actual prevalence of chlamydia is much higher. These are undiagnosed cases of the disease, as well as diseases where the indisputable role of chlamydia has been proven: bronchial asthma, pneumonia, atherosclerosis, coronary heart disease, reactive arthritis. Human infections with zoonotic chlamydia will not cease until these infections are eliminated among animals [1]. Given the general tendency towards a decrease in the infectious morbidity rate among the carnivores in Russia, there is still a persistent adverse situation as to a number of zooanthroponotic infections, in particular, regarding chlamydia [2-3].

\footnotetext{
*Corresponding author:niko-pudovkin@yandex.ru
} 
Chlamydia have one of the broadest host species among microorganisms, affecting animal species ranging from amoeba and hydra to amphibians and mammals, including humans [4].

The Chlamydiales order bacteria are eukaryotic cells obligate intracellular parasites [5].

Chlamydial infections in animals cause a wide range of clinical diseases that do not have clear signs. Chlamydial infections are clinically manifested as a disease syndrome called ornithosis or psittacosis in birds and mammals, which includes pneumonia, air sacculitis, and enteritis. Other distinctive manifestations of chlamydial disease include abortion and conjunctivitis, encephalomyelitis, and polyarthritis in mammals. When stress factors are activated, chlamydial infection may have a severe, systemic, and sometimes fatal course of the disease [6-7].

Confirmation of chlamydial infection usually requires obtaining an appropriate clinical sample from the animal, followed by direct detection of the bacterium using an applicable laboratory diagnostic test: direct impression smears and cytological staining, agent isolation on cell cultures, immunofluorescence tests, enzyme immunoassays, or tests based on nucleic acids amplification $[8,2]$.

The chlamydial infection treatment requires using broad-spectrum antibiotic drugs. Veterinary practice favours preparations providing a high level of active substance in the lung parenchyma for several days after a single injection due to the phagocytic cells being saturated with such an antibiotic [9].

Such a substance, azithromycin, is a semisynthetic representative of the "new" macrolides group, which was synthesized in 1983 by incorporating a nitrogen atom into the 14-membered erythromycin lactone ring [10].

Azithromycin used to good advantage in human and veterinary medicine is associated with high therapeutic efficacy of the antibiotic and optimal pharmacokinetic properties, a convenient dosage regimen and high tolerability [10].

High antibacterial activity, post-antibiotic effect, tissue tropism in the inflammation focus make azithromycin a promising drug to be applied in veterinary practice to treat respiratory infections of farm animals. Taking into account the limited use of azithromycin in veterinary medicine, many aspects of its effect on chlamydial infection have not yet been properly studied, which fact determines the relevance and scientific novelty of our research.

The purpose of our research was to study the prevalence, clinical progression and treatment of Chlamydia in cats with an azithromycin-based drug.

\section{Materials and Methods}

The research was conducted onunder the aegis of Saratov State Vavilov Agrarian University (aka SSAU named after N.I. Vavilov), the City of Saratov, and the "ChanceBio" veterinary laboratory, the City of Moscow.

Samples for testing were collected from domestic cats checked into the animal clinics of Moscow.

Statistics were collected based on outpatient registers and clinical records of cats of different breeds and ages as of 2019.

In order to study the epizootic manifestation of chlamydial infection in the carnivore population in urban areas, as well as to collect the initial data for improving the epizootological diagnosis of this pathology, we analyzed and subjected to statistical processing: statistical reviews and reports of veterinary laboratories, animal health centers, laboratory test results (molecular biological, hematological, biochemical) and clinical and epizootological studies in diagnosing chlamydial infection in cats.

The indicators of the small pets most common infectious pathology were studied by conducting epizootological surveillance with determining the nosological profile and 
specific nosologic unit, along with estimating the sub- and interpopulation boundaries of its epizootic manifestations.

The subject of the research was the degree of chlamydia incidence, the infected cats' age, gender, clinical manifestations of the disease.

The preliminary medical history taken contained the indication of the gender, age, and breed of the animal, ascertained the animal care conditions, type of feeding, vaccinations available, mating, as well as infectious and non-contagious diseases suffered.

To diagnose chlamydia, a polymerase chain reaction (PCR) was performed. The main targets to detect the Chlamydia bacteria are the nucleotide sequence of a species-specific cryptic plasmid, the major inner membrane protein sequence, and ribosomal genes. PCR diagnostics is highly specific; its adequate sensitivity makes it possible to diagnose not only acute, but also latent infections in a clinically significant titer, and to identify the pathogen within 4.5-5 hours.

Laboratory samples for the PCR diagnostics were obtained using disposable sterile probes with improved adsorption. Swabs were collected from the upper and lower eyelids conjunctiva of both eyes, or from the apical vaginal vault or preputium and urethra, from the nasal mucosa, depending on the indications. In mature animals, samples were taken from both the conjunctiva and the genital mucous membranes. With varying degrees of damage to the animal's eyes, the swabs were collected first from the healthy eye, then from the affected one.

To study the effect of Azithronit on the feline body, under the analogue principle, 2 groups of animals were formed, each containing 6 cats.

The Azithronit drug was administered $0.5 \mathrm{ml}$ per animal, 1 time per day, for 7 days.

Hematological parameters were determined using the IDEXX Laser Cyte hematological analyzer, while the biochemical parameters were determined using the IDEXX Catalist analyzer (USA).

The quantitative readings were statistically processed with the Student criterion calculated on a personal computer using the Microsoft Excel variation statistics routine program.

\section{Results}

The first stage of the research was devoted to the study of chlamydia prevalence in cats, depending on their age. A total of 3,388 samples for chlamydia were studied in 2019, of which 243 proved to be positive. The overall infection rate of the population totalled $7.2 \%$. 


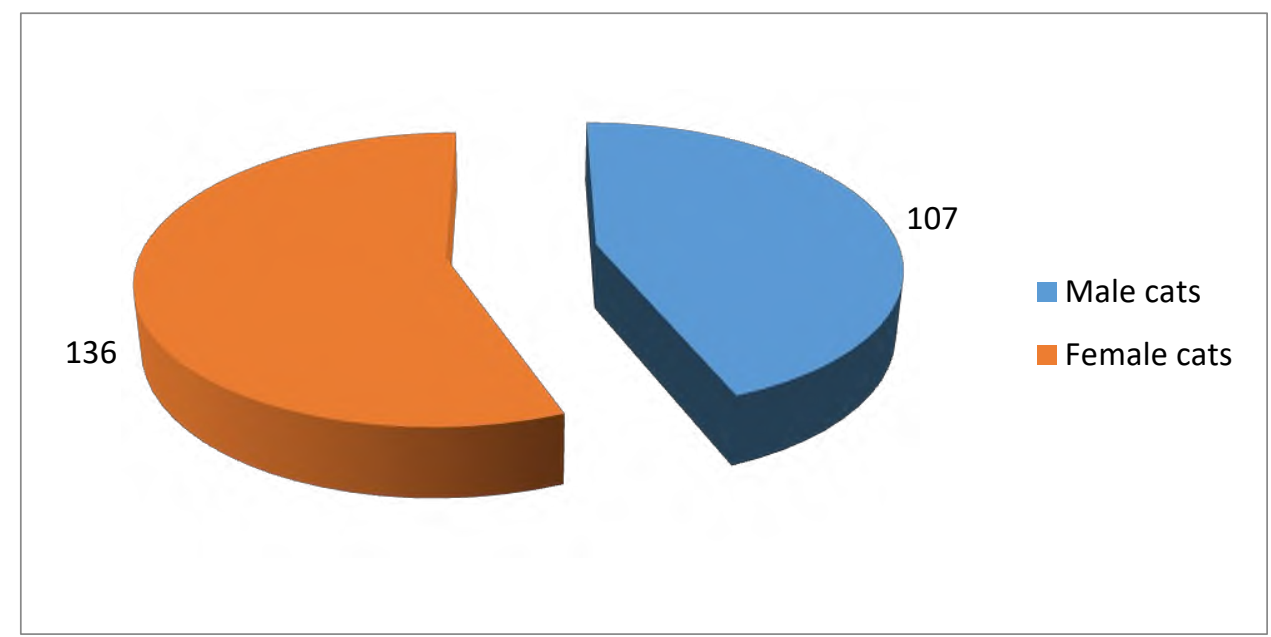

Fig. 1. Chlamydia prevalence ratio (in animals) depending on the animal gender $(n=243)$

The percentage ratio of the chlamydia antigen detected in male and female cats was approximately the same (Fig. 1). In female cats, the chlamydia antigen detection percentage is higher than in males $-56 \%$ versus $44 \%$, respectively.

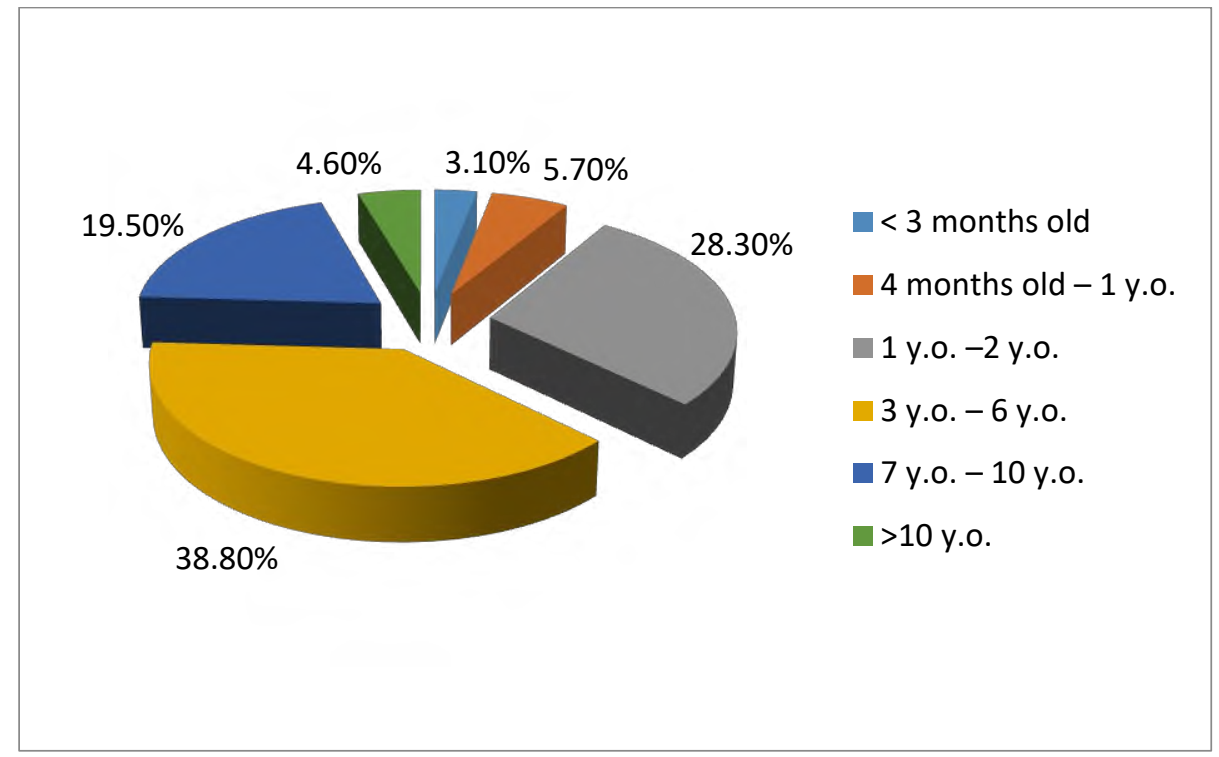

Fig. 2. Chlamydia prevalence ratio (as \%) depending on the animal age $(n=243)$

It has been established that the majority of the pet owners' complaints regarding suspected chlamydia in their animals (testing animals with clinical symptoms or for prophylactic purposes) falls on the age from 3 to 6 years old (the active reproduction age), while the largest share of positive results falls on the same age (Fig. 2). Animals aged 1 to 2 years old account for $28.3 \%$ of infected species. In animals aged 7 to 10 years old, $19.5 \%$ of chlamydia infection cases were reported. In 2019, the share of affected cats under the age of 3 months old amounted to $3.1 \%$, of those aged $4-12$ months old totalled $5.7 \%$, and of those over 10 years of age made $4.6 \%$. Thus, the greatest age-related susceptibility of cats to 
chlamydia is established in the adult life period (ranging from 1 to 10 years old). The major forms of chlamydial infection in cats are shown in Figure 3.

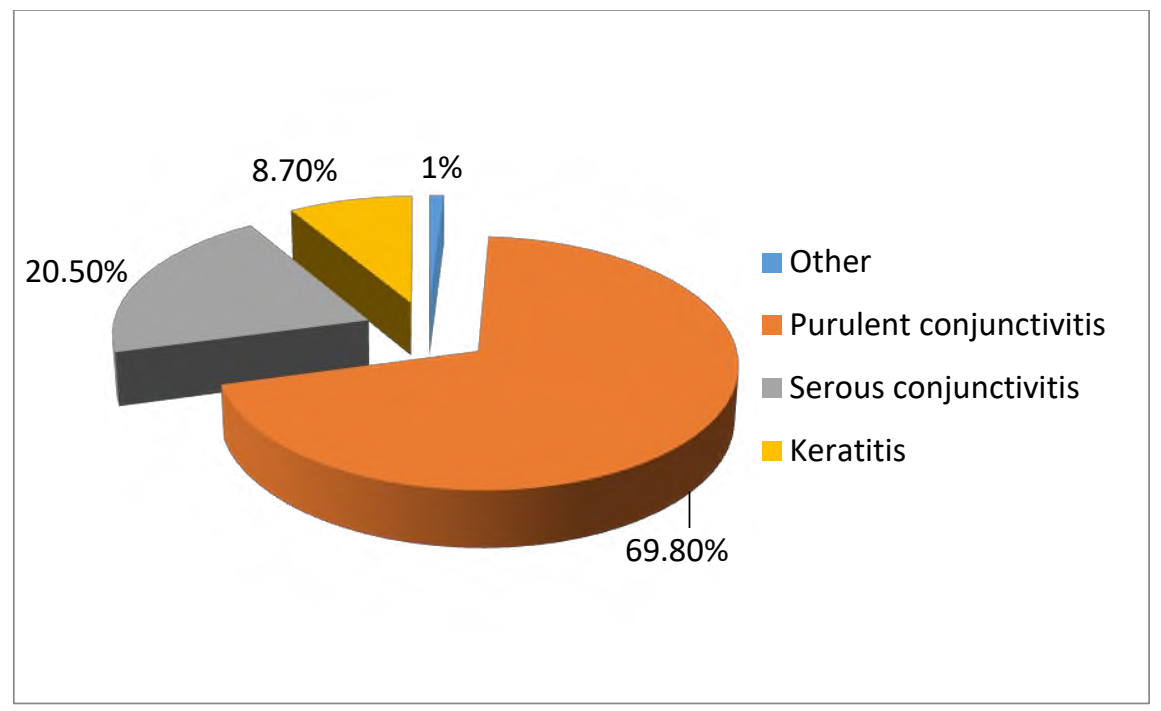

Fig. 3. Chlamydia forms (as \%) in cats $(\mathrm{n}=243)$

The major forms of chlamydial infection manifestation were those of purulent and serous conjunctivitis $-69.8 \%$ and $20.5 \%$, respectively (Fig. 3). Keratitis accounted for $8.7 \%$ of the chlamydial infection cases. Other cases of chlamydia forms (rhinitis, abortion, vaginitis, etc.) accounted for $1 \%$ of cases. Thus, the most common forms of chlamydia in cats in Moscow are those of purulent and serous conjunctivitis.

The main symptoms of chlamydial infection in cats are presented in table 1.

Table 1. Symptoms of chlamydial infection in cats (as \%)

\begin{tabular}{|l|l|c|}
\hline No & \multicolumn{1}{|c|}{ Symptoms } & Cases as \% \\
\hline 1. & Eye discharge: & \\
& purulent & 77.3 \\
& serous & 21.3 \\
& mucoid discharge & 5.9 \\
\hline 2. & Hyperemia, conjunctival edema & 64.9 \\
\hline 3. & Cornea darkening & 9.1 \\
\hline 4 & Other & 1.4 \\
\hline
\end{tabular}

Most often, the clinical picture of chlamydia is accompanied by purulent $(77.3 \%)$ and serous $(21.3 \%)$ discharge from the eyes, conjunctival hyperemia and conjunctival edema $(64.9 \%)$ and cornea darkening $(9.1 \%)$.

The recovery rate after the treatment with Azithronit made 97\%.

Next, we studied the effect of Azithronit on the morphological blood parameters. The findings of the research as to the effect of the Azithronit preparation are presented in table 2.

Table 2. Blood chemistry values for cats

\begin{tabular}{|l|l|l|l|l|}
\hline Blood values & Unit & $\begin{array}{l}\text { Normal } \\
\text { range }\end{array}$ & Untreated & $\begin{array}{l}\text { After } \\
\text { treatment }\end{array}$ \\
\hline Total bilirubin & $\mu \mathrm{mol} / 1$ & $3.0-12.0$ & $8.47 \pm 0.80$ & $7.95 \pm 0.69$ \\
\hline Direct bilirubin & $\mu \mathrm{mol} / 1$ & $0.0-5.5$ & $2.92 \pm 0.22$ & $3.27 \pm 0.26$ \\
\hline
\end{tabular}




\begin{tabular}{|l|l|l|l|l|}
\hline $\begin{array}{l}\text { Aspartate } \\
\text { aminotransferase (AST) }\end{array}$ & $\mathrm{u} / \mathrm{l}$ & $9-29$ & $26.83 \pm 1.89$ & $12.00 \pm 0.63^{*}$ \\
\hline $\begin{array}{l}\text { Alanine } \\
\text { aminotransferase (ALT) }\end{array}$ & $\mathrm{u} / \mathrm{l}$ & $19-79$ & $50.50 \pm 4.22$ & $54.67 \pm 4.61$ \\
\hline $\begin{array}{l}\text { Alkaline phosphatase } \\
(\mathrm{AP})\end{array}$ & $\mathrm{u} / \mathrm{l}$ & $39-120$ & $31.67 \pm 2.22$ & $56.50 \pm 2.40^{*}$ \\
\hline Creatinin & $\mu \mathrm{mol} / 1$ & $70-165$ & $110.83 \pm 6.97$ & $123.00 \pm 9.28^{*}$ \\
\hline Blood urea & $\mu \mathrm{mol} / 1$ & $5.4-12.1$ & $8.48 \pm 0.68$ & $8.50 \pm 0.57$ \\
\hline$\alpha$ - Amylase & $\mathrm{u} / 1$ & $500-1500$ & $914.00 \pm 73.58$ & $949.83 \pm 71.66$ \\
\hline Blood glucose & $\mu \mathrm{mol} / 1$ & $3.3-6.3$ & $4.70 \pm 0.22$ & $4.80 \pm 0.23$ \\
\hline $\begin{array}{l}\text { Lactate dehydrogenase } \\
\text { (LDH) }\end{array}$ & $\mathrm{u} / 1$ & $50-495$ & $135.5 \pm 9.74$ & $136.33 \pm 7.89$ \\
\hline Total protein & $\mathrm{g} / 1$ & $54-77$ & $66.5 \pm 1.48$ & $72.17 \pm 1.91^{*}$ \\
\hline
\end{tabular}

Note: the significance of differences relative to the pre-dose blood sample: ${ }^{*}-\mathrm{p} \leq 0.05$

It has been established that all the parameters under study were within the physiological standard for the given animal species. There was a significant 2.2 times decrease in aspartate aminotransferase compared to the initial level. However, there was an increase in the activity of alkaline phosphatase by $43.9 \%$, the activity remaining within the physiological standard, though.

No hard evidence of substantial increase in the amount of total bilirubin in blood serum was detected; the level of total bilirubin decreased by $7 \%$, however, there was an increase in the amount of direct bilirubin by $11 \%$ compared to the initial level. A slight increase by $10 \%$ versus the initial value was detected in the creatinine level.

No hard evidence of substantial differences in the activity of alanine aminotransferase, $\alpha$-amylase, lactate dehydroginase and the content of urea and total protein in the blood serum was detected.

The next stage of our research was devoted to studying the effect of Azithronit on the white blood cell differential (WBCD) in cats.

The findings of the research are presented in table 3.

Table 3. Effect of Azithronit on the white blood cell differential (WBCD) in cats

\begin{tabular}{|l|l|l|l|l|}
\hline Blood values & Unit & Normal range & Untreated & $\begin{array}{l}\text { After } \\
\text { treatment }\end{array}$ \\
\hline White blood cells (WBC) & $10^{9} / 1$ & $5.5-19.5$ & $14.25 \pm 0.80$ & $17.25 \pm 2.99^{*}$ \\
\hline \multicolumn{5}{|c|}{ White blood cell differential (WBCD): } \\
\hline Monocytes (MON) & $\%$ & $1-4$ & $2.00 \pm 0.58$ & $2.00 \pm 0.26$ \\
\hline Lymphocytes (LYM) & $\%$ & $20-55$ & $38.19 \pm 1.07$ & $38.17 \pm 1.01$ \\
\hline Basophils (BAS) & $\%$ & $0-1$ & - & $0.83 \pm 0.03$ \\
\hline Eosinophils (EOS) & $\%$ & $1-4$ & $0.23 \pm 0.33$ & $1.00 \pm 0.49^{*}$ \\
\hline Band neutrophils & $\%$ & $0-3$ & $1.58 \pm 0.22$ & $1.10 \pm 0.22^{*}$ \\
\hline Segmented neutrophils & $\%$ & $35-75$ & $58.00 \pm 1.29$ & $56.90 \pm 1.30$ \\
\hline
\end{tabular}

Note: the significance of differences relative to the pre-dose blood sample: $*$ - $\mathrm{p} \leq 0.05$

When analyzing the research results presented in table 2 , it has been established that the white blood cells count after Azithronit administering increased from $14.25 \pm 0.8010^{9} / 1$ to $17.25 \pm 2.9910^{9} / 1(+21.1 \%)$.

It has been found that the level of eosinophils increased 4 times, while the level of neutrophils decreased by $30.4 \%$ compared to the initial value. The collocation of eosinophils and neutrophils appears to be associated with the eosinophils chemotactic function.

\section{Discussion}


The data on the chlamydia prevalence in animals in Russia are sparse, and most of them relate to farm animals such as sheep, cattle and pigs.

Pets such as domestic cats are considered loyal friends of humans; however cats can be important sources of chlamydia infection in humans [11].

The role of chlamydia in domestic animals as zooanthroponoses has been repeatedly described in the specialist literature. So, cats become infected with almost all chlamydia species [3].

Several studies have reported the $\mathrm{C}$. felis prevalence in cats in various regions. For example, Halánová $\mathrm{M}$ et al. [12] used the direct immunofluorescence method and found a total C. felis prevalence of $45.16 \%$ among cats in Slovakia. According to the results of our research, the population infection rate was lower (7.2\%). Millán J, Rodriguez A. found 27\% positive responses to chlamydia in serum samples of European wildcats using enzymelinked immunosorbent assay [13].

Human infection occurs by aerosol or contact in close interaction with a pet, in which the infection can occur both in the form of an acute or chronic respiratory disease or conjunctivitis, and latently [14].

Our studies using the polymerase chain reaction have demonstrated that chlamydia is widespread in cats under one year old, which is consistent with the results of studies by other authors. However, although these differences were not statistically significant, in this study we found a higher prevalence of antibodies in older animals. The female and male cats morbidity was different, yet, the statistical analysis did not show substantial differences, which is consistent with earlier studies [11].

A fairly high prevalence of chlamydia can be referred to the fact that far not all owners of the infected animals, namely, of cats, seek advice of veterinary specialists. The share of chlamydia in carnivores versus the general pathology of infectious diseases is constantly increasing, since according to the scheduled antiepizootic measures, regional laboratories conduct diagnostic tests for chlamydia. The incidence of carnivore chlamydia is registered throughout the year, reaching its highest intensity in spring.

A decrease in the AST activity can be considered as a favorable sign indicating the cessation of hepatocyte cytolysis in the animals bodies.

The lowering total bilirubin level indicates a reduction in hepatic inflammation of bacterial origin.

An increased white blood cells count in the body may be caused by bacterial products, components of the complement system (C5a), products of the lipoxygenase pathway of arachidonic acid metabolism (LT B4), cytokines (interleukin-8) and other factors [15].

An increased eosinophils count appears to be associated with the fact that the eosinophils major basic protein activates the function of neutrophils; we have also detected an increase in the level of the neutrophils toxic function during the interaction of eosinophil peroxidase with target cells [2].

The results of this study indicate that chlamydia is widespread among cats in Moscow, which suggests that this pathogen is a ponderable cause of eye diseases in these animals. Chlamydia is a zoonotic pathogen, therefore, to prevent human diseases, it is recommended to maintain hygienic conditions and carry out affected cats and dogs surgical treatment.

\section{References}

1. S. Gottlieb, C. Deal, B. Giersing, H. Rees, G. Bolan, C. Johnston, et. al., Vaccine, 34, 2939-2947 (2016) doi: 10.1016/j.vaccine.2016.03.111

2. M. Pennington, J. A. Capriotti, G. R. van de Walle, The Veterinary Journal., 241, 3841 (2018) doi: 10.1016/j.tvj1.2018.09.011. 
3. M. Rahnama, K. A. Fields, Microbes and Infection., 20(7-8), 445-450 (2018) doi: 10.1016/j.micinf.2018.01.002.

4. J. Stiles, Veterinary Journal., 201(2), 161 - 173 (2014) doi: 10.1016/j.tvj1.2013.11.018

5. L. Párducz, I. Eszik, G. Wagner, K. Burián, V. Endrész, D. P. Virok, Letters in Applied Microbiology, 63, 260-267 (2016) doi: 10.1111/lam.12625

6. M. Puolakkainen, P. A. I. Saikku, Infectious Diseases (Fourth Edition), 2, 1676-1680 (2017) doi: 10.1016/B978-0-7020-6285-8.00188-X.

7. M. M. Sarmeidani, P. Keihani, P. Rezaei, H. Momtaz, Sh Heidari, Iraqi Journal of Veterinary Sciences, 31(2), 91-94 (2017) doi:10.33899/ijvs.2017.145603.

8. D. Onorini, M. Donati, H. Marti, R. Biondi, Aurora Levi, et al. Veterinary Microbiology, 233, 11-30 (2019) doi: 10.1016/j.vetmic.2019.04.012

9. H. C. Cheong, C. Y. Q. Lee, Y. Y. Cheok, G. M. Y. Tan, C. Y. Looi, W. F. Wong, Microorganisms., 24, 7(5), 146 (2019) doi: 10.3390/microorganisms7050146.

10. M. Desai, H. Zhang, H. Fan, BMC Res Notes, 13(1), 28 (2020) doi: 10.1186/s13104020-4893-9.

11. D. Burnard, A. Polkinghorne, Vet Microbiol., 30(196), 78-84 (2016) doi: 10.1016/j.vetmic.2016.10.018.

12. G. Kozlov, et al., Bioindication for the Search of Microorganisms-Destructors. Advances in Intelligent Systems and Computing 676-684 (2020) doi: 10.1007/978-3030-57453-6_64

13. J. Millán, T. Proboste, I. F. de Mera, A. Chirife, J. de la Fuente, L. Altet, Ticks and Tick-borne Diseases, 7, 284-290 (2016) doi: 10.1016/j.ttbdis.2015.11.003

14. A. Polkinghorne, N. Borel, M. Heijne, Y. Pannekoek, Clinical Microbiology and Infection., 25(2), 131-132 (2019) doi:10.1016/j.cmi.2018.10.015.

15. M. M. Weber, J. L. Lam, C. A. Dooley, N. F. Noriea, B. T. Hansen, F. H. Hoyt, A. B. Carmody, G. L. Sturdevant, T. Hackstadt, Cell Reports., 19(7), 1406-1417 (2017) doi:10.1016/j.celrep.2017.04.058 